\title{
Evaluating ERP System Merging Success In Chemical Companies: System Quality, Information Quality, And Service Quality
}

https://doi.org/10.1515/eng-2020-0003

Received Nov 28, 2019; accepted Jan 20, 2020

\begin{abstract}
This study is aimed to analyze success of the Enterprise Resource Planning (ERP) System Merging in Chemical Company Singapore that acquired two companies. The success component of ERP system success is using DeLone and McLean success model with qualitative method. The research methodology used detail interview with project implementation team, ERP consultants (8 informants) to get more detail from ERP system merging with information and collected supporting data from the ERP system itself. The result shows that ERP System Merging succeed to increase the system quality of Chemical Company which acquired two companies into one ERP system. It was depicted by the increment of easiness on using the system. The information much more integrated and accurate after the ERP system merging. Meanwhile service quality was increased because of all incidents now monitored in one efficient log system and handled by experienced IT application support team.
\end{abstract}

Keywords: ERP System Merging; ERP System Merging Success; System Merging

\section{Introduction}

Currently only few qualitative researches for ERP system merging related to system quality, information quality and service quality success which brought attention to

\footnotetext{
*Corresponding Author: Ford Lumban Gaol: Computer Science Department, BINUS Graduate Program - Doctor of Computer Science, Bina Nusantara University, Jakarta 11480, Indonesia; Email: fgaol@binus.edu

Intan Puryasana: Information Systems Management Department, Binus Graduate Program, Bina Nusantara University, Jakarta 11480 , Indonesia; Email: intan.puryasana@binus.ac.id

Tokuro Matsuo: Advanced Institute of Industry Technology, Tokyo, Japan; Email: matsuo@aiit.ac.jp
}

O̊pen Access. (C) 2020 F. L. Gaol et al., published by De Gruyter. (Cc) BY License researcher to contribute on how success the ERP system merging which impact to the company as organization. [11] has categorized ERP system merging literatures into 3 areas; the relationships between strategic objectives and IT integration [14], second is organizational implementation success factors [15], and third is technical aspects [16, 17].

The Chemical Company has objective to align its business strategic with IT integration. The Chemical Company in Singapore has acquired 2 companies, despite of having different line of businesses and systems. Streamlining all three companies with different business lines is a big challenge and it is not an easy task. Day to day business processes related to financial transaction also will be impacted. During the acquisition and transition activities of two companies into one Chemical Company, there are some business continuity risks and system disruption risks. This research also will study on how Chemical Company successfully combine the other two companies into one ERP system. Business continuity risk covers the potential disharmony and loss key person, settlement failure and compliance failure. Meanwhile system disruption risks such as unsuccessful data migration, misalignment on business processes, incorrect system configuration were the challenges while doing the ERP system merging.

\section{Materials and Methods}

This research uses qualitative approach with case study because researcher would like to get deeper understanding and more specific regarding ERP System Merging Success in Chemical Company Singapore Using DeLone And Mclean' Theory: The Analyses of System Quality, Information Quality, And Service Quality using DeLone and McLean models [8] in changing business environment. Researcher has decided to use case study as research method because the design, development and implementation of Enterprise Resource Planning (ERP) cannot be wholly understood in isolation of its context, hence a contextual ap- 
proach is necessary. As the opposite of other empirical research methods, the case study allows the analysis of a contemporaneous phenomenon in its real-life context, when the boundaries between phenomenon and the context are not clearly identified and differentiated. The analysis of this research has enabled the researcher to define and do scoping for the requirements that were specified for implementing the ERP system merging. Interviews with project implementation team and project manager who was involved in day to day ERP System merging implementation also helped author to get detail information from direct source who had done the actual ERP system work [12] The main ERP objective is to increase enterprise operating efficiency by integrating business processes and decreasing costs $[4,12]$. ERP make the connection from each different department with diverse needs to interact each other by sharing the same information in a single system and platform. Hence ERP will increase cooperation and interaction between all business units in an organization on this basis [19].

\section{Results}

Research was done in consulting office branch located in Singapore after the project implementation project passed through one year after, to see the ERP system journey up to now. The interview was done per individual consultants in each workstream or area to have the proper representative of their expertise and to get more variety of their observation and experience and to project manager to get overall overview regarding success of the merging of system including the merging of the business for Chemical Company.

\subsection{ERP System Merging Success in details}

\subsubsection{System Quality}

\section{Interview Result}

The success of ERP system merging was analyzed accordingly during interview and researcher has identified some keywords which relate to DeLone and McLean's information system success component with each of their attributes and characteristics.

To be noted here, some of the system quality's attributes may not be significant enough to be represented during the keyword identification in the interview, hence further analysis is required to synthesize the relationship between the information system success component.

\subsubsection{Ease of use Interview Result}

To understand the meaning of ease of use, we can refer to "the degree to which a person believes that using a particular system would be free of effort." If we dig down further the definition of "ease": "freedom from difficulty or great effort." The effort is a finite resource that a person may allocate to the various activities for which he or she is responsible [7]. There are some differences before and after ERP system migration because of acquisition process in company B and company C. When the company B and company $\mathrm{C}$ run on their own ERP system, they had problems on information system audit findings because of segregation of duties, lack of integration in some business processes, slow reporting and there are non-standard processes which may lead new user has difficulties to do transaction in the system.

After the ERP migration to Host Chemical Company, company $\mathrm{B}$, and company $\mathrm{C}$ need to follow the standardized business processes which already complied with financial audit hence new user also easily follows the new standardized procedures and processes in the host company code. The user guidance and user manuals are established across the business unit.

As mentioned by informant AT, the interview quotes from AT "They are always then having any major issue during an audit, the only recommendation only, meaning now flaws were found, the only recommendation, you can improve the current processes"

He mentioned about the process of merger for the company because of there are some problems related to Audit findings for company B and company $\mathrm{C}$ before the acquisition by Chemical Company which specifically related to Segregation of Duties (SOD), for example the person who raise the purchase order also as the person who is doing inventory movement record because of the size of the company, hence there is urgency to merge the company as well as their system to improve the efficiency of the process. AT has given one example one company as a reference which has better audit result which can be used as a base or main reference for other companies which need to be merged with the company which has a better practice.

This analysis is supported also by another informant (PH) who has given input as shown, 
"Yes, correct, with the Chemical Company, I have also that because we also redesign the way they-, um the piece of equipment and functional locations, we redesigned it. So, it's now very easier for them to look into the structure tree and they can find easily where is the piece of equipment located".

Based on the response above, we can get some points to be highlighted on how the ERP system acquisition has given impact to company B and company C users which now they can use the new system easier because host Chemical Company has implemented a new way of structuring and providing a better way to find equipment master data in warehouse during data entry hence users observed and experience the new way of entering master data easier.

This analysis is supported also by another informant (AN) who has given input as shown,

"Yeah actually like before merging they were using 2 totally different system to maintain their HR data, including like personal data, and as well as administration data, as well as basically mainly they are using travel management module in Company $C$, so these other 2 modules are supporting, so it's like HR, having like tedious work to maintain into different like system, so after the Chemical Company project, it's all come into one system, so like the workload of HR dramatically reduced.

\subsubsection{Ease of Learning Interview Result}

Ease of learning is one of the components of system quality measurement. One of interviews with Informant, AN. He mentioned "Yeah, after training and all like they are more comfortable with the travel system, and now it's really effective in using it"

This shows the user had some experience in learning a new system after the company $B$ and company $C$ ERP system merging. The researcher also observed users can handle their daily job using the same standardized job aid and standard operating procedures (SOP) from the merged system. The key user from Chemical Company also willing to share their knowledge with the user from company $\mathrm{B}$ and company $\mathrm{C}$ which they need to adopt new ways of working as one team in one company. The user also has access to Chemical Company SAP training environment which they could practice more to learn how to enter their daily transactions and speed up their learning time using job aid card.

\subsubsection{Flexibility Interview Result}

Flexibility usually is linked with agility as well though flexibility tends to how far the system could answer the business challenge in this modern era. Based on discussion with one of the informants (RA) as developer lead, he has mentioned that "even for the, even any modification also now it is easy because we already created some, one SAP function module to segregate based on the division. So far that is easy even any new developer also comes also they can easily identify and fix the problem, so even not only for the reports, interfaces, and forms, everything we follow the same logic and it implemented successfully."

Belkhamza [5] has mentioned that system quality consists of ease of use, response time, system flexibility and system integration. From point of view organization structure, Chemical Company, company B and company C which previously represented by 3 company codes (Chemical Company, company B, and company C) and consist of 10 divisions. Now all are merged to become one Chemical Company with 8 divisions. With this one company code, now Chemical Company has more flexibility to adapt any changes if required compared to the previous state which has 3 company codes with their own business processes, user, roles and authorization. For example, there is a need to change the financial reporting at profit center level, now with only one company codes, the intercompany transaction is reduced drastically and company able to produce the balance sheet per profit center faster because of all data now in one Chemical Company.

\subsubsection{Integration Interview Result}

Master data in Human Resources and Travel Management module are integrated into one system platform as AN said hence the system will be automatically generate posting use system standard report more rather than excel spreadsheet.

Inquiries with Informant AN stated; "Yes, that is the main advantage, like before like master data in some other place and travel, so a lot of manual work involved in that time. Also, now it's totally different, like everything totally integrated into one system. “

From this interview quotation, we can get some insights that before the merging of two company the reports were lacking integration because of data were scattered in several database repositories. 


\section{Supporting Data}

The researcher also gets a sample of the travel management screenshots as supporting data to show the employee number merging from company B and company $\mathrm{C}$ into Chemical Company with one number range for all. Above figures show Company B and company $\mathrm{C}$ has migrated their employee master data into Chemical Company with their unique id with different number ranges but it is still within the Chemical Company range to ensure overall employee master data are aligned. Now all the travel expense management processes such as travel advance, travel expense reimbursement are integrated with payroll for company code B and company code C's employee under Chemical Company integrated system in SAP HR. Hence after ERP system merging, all data are located in one single place which create the data integration accordingly.

\subsubsection{User Requirement Interview Result}

A successful information system is also measured by whether user requirements can be fulfilled by the system which provides expected output as expected by the business user. One of sample user requirement is found during the research on Chemical Company which has a project to merge other two affiliate companies to have one single system for human resources management to reduce tedious work and increase the speed of human resources data recording and processing.

Arachchi, S.M., Chong, S-C [1] has done the research on quality assurance and quality control in ERP system implementation. Data cleansing and data integrity are the key factors for successful ERP system implementation. Project management needs to apply quality assurance to ensure ERP system implementation achieve the project goals and brings benefit for company. AN as an informant in SAP HR has mentioned below "Yes, that is the main advantage, like before like master data in some other place and travel, so a lot of manual work involved in that time. Also, now it's totally different, like everything totally integrated into one system, and, so everything like they come to one place, so integration ways now is very easy, and again my major like integration with FI (Financial Accounting). So now it's like, it starts fully automated and it's going to thebecause that time also they, FI totally in a different system, now it going to the same place, so everybody's job reduced."

Based on the discussion above, the successful information system can address the business user accurately, even though during the system integration testing and user acceptance test, there will be more adjustment or finetuning but with the proper functional specification, user requirement can be captured and implemented as required by the business user.

\subsubsection{System Accuracy Interview Result}

System accuracy refers to the valuable information provided by a system that met what the user has expected. In one of the discussions with the informant, the researcher has found the importance of system accuracy in the information system.

Attayah, O.F, Sweiti I.M. [2] concluded that ERP system implementation have significant impact to accounting information and also improve timeliness and relevancy. In general, ERP system has improved management to increase decision making efficiency by leveraging the relevance of accounting information. Informant GA has highlighted the system accuracy in the interview as follows; "Okay for example I can say, every month we are using the part of the settlement report right, so the settlement report is integrated with the finance and the logistic, so what happened, so how they utilize at some extend for example the information comes from the logistic team, so they have to execute from one of the reports from logistics other one report from the finance, then they have to merge this two reports to extend and validate."

This is the sample of the system's accuracy impact significantly to the business of the company. Only the right information can support the business user to make a decision. One sample is a consignment settlement report which covers the report to show how much revenue which come from the consignment sales which involve 2 departments sales and finance to produce this report.

\section{Supporting Data}

The researcher has collected important information to shows sales quantity also is important to be retrieved in some of the reports which can be reconciled quickly. Sales quantity from Controlling Profitability Analysis is matched against the sales quantity from logistic consignment report as one of the checking criteria to ensure both reports are showing the same sales quantity figure. The researcher asked further inquiries regarding settlement report and informant GN has provided a sample of the settlement report screen for further analysis. In this screen sample, there are some reports options to run the different output of reports. 
For example, the settlement report will give the information for the Finance Department how much total sales including the adjustment using credit and debit memo to affiliates company as Chemical Company supplier. With the merging of the company $\mathrm{B}$ and company $\mathrm{C}$ into Chemical Company all the information regarding consignment settlement report can be gathered in one place for their credit and debit memo information pertaining consignment settlement and the report can be generated promptly and also it has the integration with financial accounting hence either logistic or finance department can take this benefit on this customized settlement report. Myers [11] highlighted on the ERP integration strategy that give business benefits for short term and long term.

\subsubsection{System Features Interview Result}

System features in the new system after the acquisition for company B and company $\mathrm{C}$ in the Chemical Company. This is supported by an interview with one of the informants GN, he cited that with the new system in Chemical Company for the journal entry now can be done either using a manual journal entry or user may use upload program as a tool to speed up the accounting entry posting. The program also has features to do park and posting.

GN has cited during the interview as follows "Okay, actually how it is the system flexibility now, for example, user usually they wanted to manually, they can enter the entry also manually or if you want to do the upload, or can use the GL upload program too, uploading to them, multiple entries by the one-time upload". Based on detail discussion with GN, there is an enhancement program to help the user to speed up their day to day work. The user now can perform journal in one platform with a new feature to do park functionality which allow the user to edit the document before they do the posting. Hence the journal entry now is more accurate and more precise because of the ERP System merging. The new feature can collect the data in a one-time process and give the output promptly after the migration into one system. Hence after the system merging, company $B$ and company $C$ user uses only one Chemical Company as financial accounting organization unit which eliminated the intercompany transaction which previously required for a transaction between company code B with Chemical Company, or company code B with company code $\mathrm{C}$ or Chemical Company with company code C.3.1.1.8 System Sophistication

\section{Interview Result}

SAP system may be enhanced for certain purpose such as to address the unique requirement of the company which cannot be provided using standard functionality.

When the researcher checked what the informant KA said; "OK, many mostly I can say, the issues which were arising before, due to manual mistakes like the typo, or the date in the different periods, but everything is controlled now. Meaning whatever the enhancement, $O K$, in the system been operated in the new business unit also. in Such way they have their controlled way of doing business, they don't input any wrong data, there is a check for all input, for example, if they create any transactions, billing which is not in the open period of time, they open accounting period of time it will throw warning or error message upfront, so business user or logistic users when they log billing document, already they are aware this is the wrong period, by that, it is not posted to the wrong Financial (FI) period". In Chemical Company, there are some enhancements are developed related to the consignment process. This related to sales activity between one affiliate company as a manufacturing company as a product provider and the other company as the seller. The consigned product will be recorded at the seller company and seller company will report the sales using consignment settlement report. The business user may use the consignment report to get the accurate data about how much the consignment product has been sold and the allocation payment to supplier company can be calculated correctly. The period for data entry is also controlled by system and system will give errors if the period is not opened yet.

\subsubsection{Customization Interview Result}

Customization involves enhancement of the system to address specific business requirement. During an interview with SAP consultant AN as SAP Human Resources (HR) informant, there are some key points to be highlighted here; before company $\mathrm{B}$ and company $\mathrm{C}$ merge into Chemical Company, they were using two totally different systems to maintain their HR data hence their personnel data are separated and whenever there is travel expense recharge, intercompany transaction needs to be generated and reconciled. The reconciliation process takes a big effort and also increase the risk of different data between company codes. This will consume user working hours as well which they could use for review and analysis activities rather than spending effort on data reconciliation. Informant AN said; 
“It's I say, HR perspective, for the users also before they like they were in travel, perspective they were not using SAP at all for others, like so once they moved to Chemical Company like inter-charge using like traveling SAP, and now further put their purpose and all of things, it became more effective".

Because of the ERP system merger, all personnel number are stored in one database and all travel request, travel advance and travel expense settlement are now done in one system. The reconciliation processes are no longer needed, and the expense settlement can be done within one Chemical Company. User may also directly run the travel expense report immediately without any further cross-check between the company's system. From the detailed analysis and checking into the system, the researcher also can find the user now able to run the report faster.

\section{Supporting Data}

During the ERP system merging, project team has faced challenges related to system such as system configuration errors and user authorization issue hence system fine tuning and reconfiguration were needed to make company $\mathrm{B}$ and company $\mathrm{C}$ system configuration adaption in host Chemical Company.

The researcher found also in the communication email, there was problem on data integrity in sales process during user acceptance test hence the project team worked in the integration area to ensure the data flow properly from quotation converted to sales order then followed by delivery process and billing as financial activities to generate revenue.

In summary, the ERP system merging in terms of system quality success in Chemical Company are described;

a ERP system merging brings better ERP system performance since one ERP system has more advantages rather than company maintain multiple ERP systems in parallel which eventually;

- Reduce maintenance cost.

- Reduce production support time.

- Reduce Report run time.

- Reduce report reconciliation and Report extraction.

b One company as a reference which has better ERP system audit result acted as base or main reference ERP system for other companies which need to be merged will speed up the ERP system merging process because Chemical Company has reliable reference for good ERP system.

\subsubsection{Information Quality}

\section{Interview Result}

Information quality can be measured using the worth valuation of information itself. It should have the following characteristics; relevance, understandability, accuracy, conciseness, completeness, currency, timeliness and usability [8]. The information system will give valuable input and useful for decision-makers to get the information promptly and accurately.

[18] mentioned that the decision-making process will use the information that should meet a certain quality level and refers to the quality of information produced by an Information Communication Technology (ICT) system. Hence it is a critical factor to evaluate the success of an ICT system. Information quality may also relate to content, accuracy, and format of the information generated [20]. For information quality, there is a significant improvement after company $\mathrm{B}$ and $\mathrm{C}$ merged into Chemical Company. One of the informants $(\mathrm{PH})$ has mentioned "Yeah respond time, eh previously because of some customizing report, because they coded very old-fashioned way, so the response is quite slow if you have big data, a lot of data volume. But now after this implementation, the system responds very quick with the report, the extract, the report displays on this ALV report in very quick. And also, the time for them to go to each transaction also faster."

Meanwhile, $\mathrm{PH}$ also has highlighted the importance for information quality such as inventory balance for spare parts, the information must have accurate inventory quantity, the correct amount in terms of value and also the inventory location. With the correct information of inventory balance, management can make a decision more accurate for the inventory procurement to ensure Chemical Company has sufficient stock. The information provided in the report is also concise which make easier for a user to read necessary data being displayed and get the right information as required.

In other interview with GN, he said that" We have multiple currency, for example USD and the SGD and the AUD also, so they have multiple currency so the user can be based on the-for example vendor right, vendor invoice which currency they issued, based on they enter the document currency."

Based on the fact given, the reports in Chemical Company are able to differentiate between transaction currency and local currency. 


\subsubsection{Service Quality}

\section{Interview Result}

Service Quality may refer to some of the attributes such as

- Assurance

- Empathy

- Responsiveness

- number of incidents

Barker and Frolick [3] have highlighted the challenges during ERP implementation that ERP may fail for some reasons, such as challenge on communication and change management, misinterpretation of company's employee, lack of top management support and also the project teams involved in the project determines how success ERP project implementation. During the interview and data collection in Chemical Company after the merger, the number of incident tickets have been responded and also the declining trend of ticket raised by the user. Based on an interview with each of consultant, after the system went live in April 2017, Chemical Company has a positive trend for service quality, which this trend data analysis is supported by AT who mentioned "I would say the first 3 to 4 months it was more on the higher level right, so then after 3 or 4 months it came down at least 80 - 90 percent issues, from fourth month onward, again the three months I won't say it's all only support issues, there was some major enhancement also, so after they go use the system, users want to change, they want some changes this and that, and that's all announcement also came in,”

\section{Supporting Data}

The researcher collected the statistic of incident ticket raised after the system merger between company $B$ and company $C$ into Chemical Company.

\subsection{Figures, Tables and Schemes}

According to DeLone and McLean, system use is the degree and manner which business user utilizes the system capability of the information system, based on the interview result, the informant SA mentioned that "So as far as finance user concerned, they could realize the real difference, but whereas the existing logistic user all the operation all, everything the same, so no new features, like except they would have wanted the new report and anything, those requirements are all around the matters of Chemical Company Project"

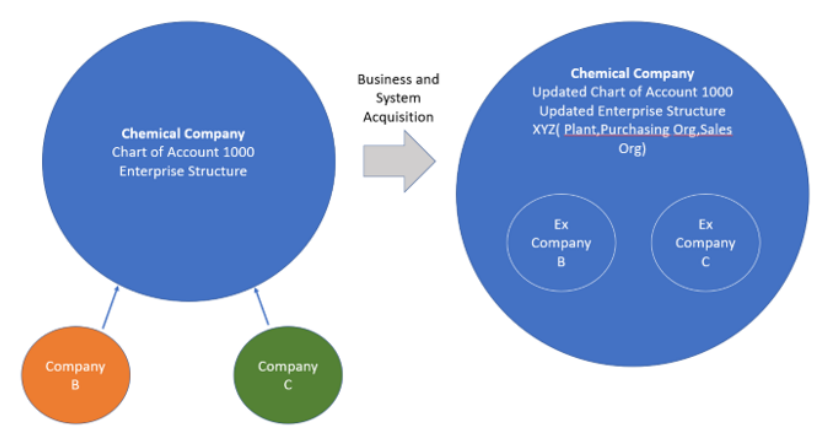

Figure 1: Company B and Company C Acquisition by Chemical Company

Incident Ticket 2017

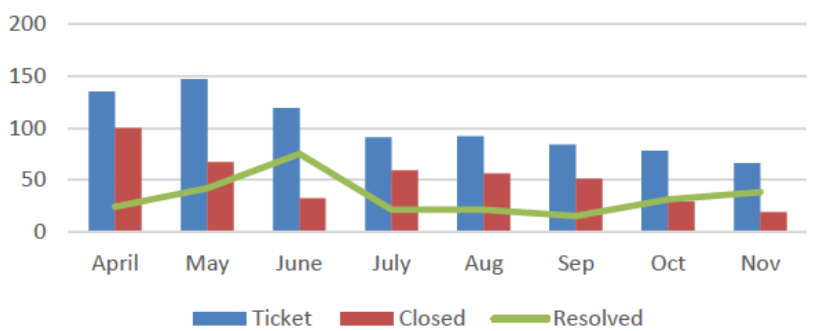

Figure 2: Incident Ticket Trend after Go Live April 2017

This concludes that the user intends to use the system more advanced and would like to utilize the capability of the system in the next higher level. The users want to use the inventory report as per their required layout and they were willingly using the report on a daily basis to help their business decision.

Below is the summary of research result that depict before and after ERP system merging's condition.

Curko, K., Stepanic D., Varga M. [6] in the research of strategic success factors in ERP implementation such as top management support, solid project management and change management team and implementation strategy. 


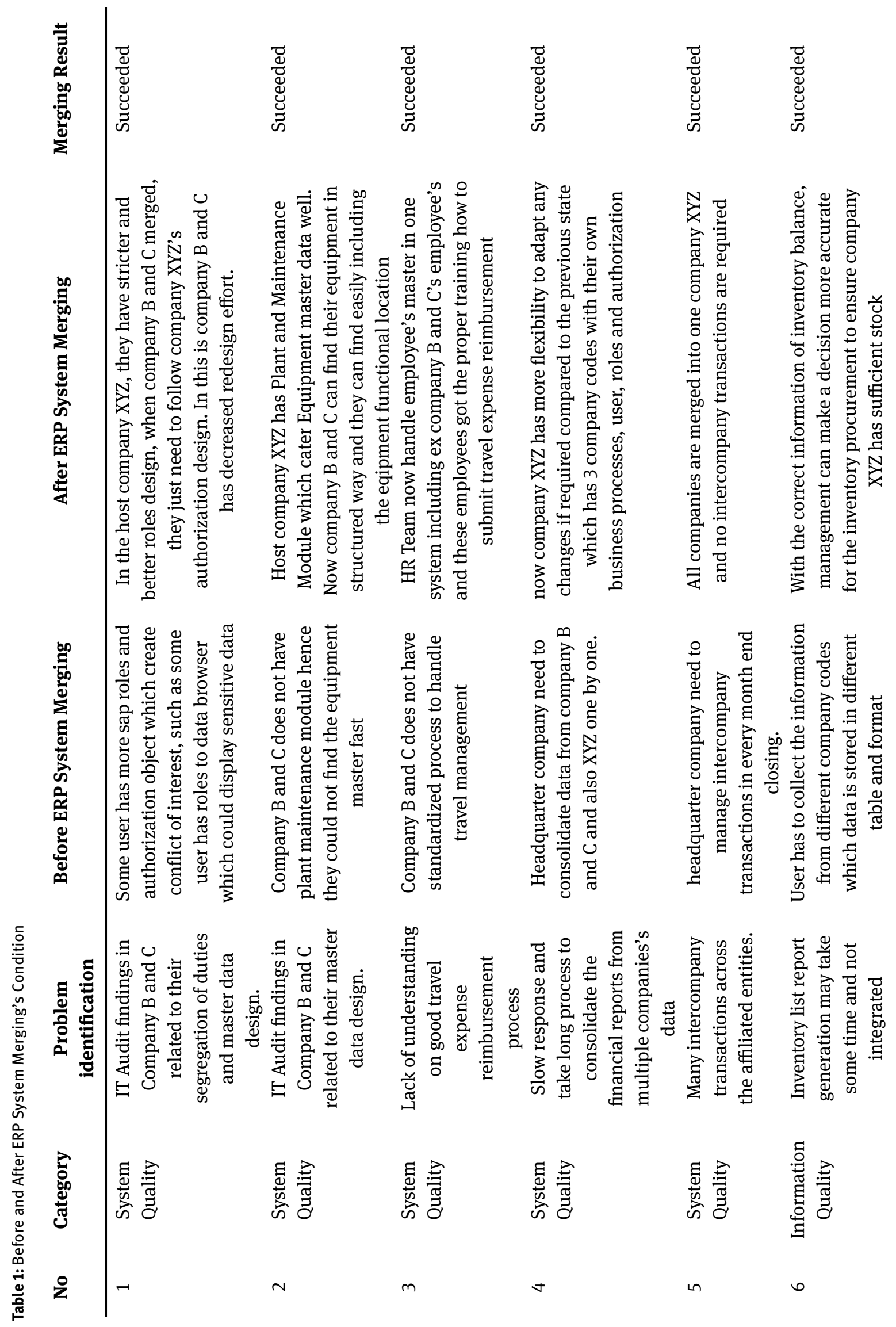




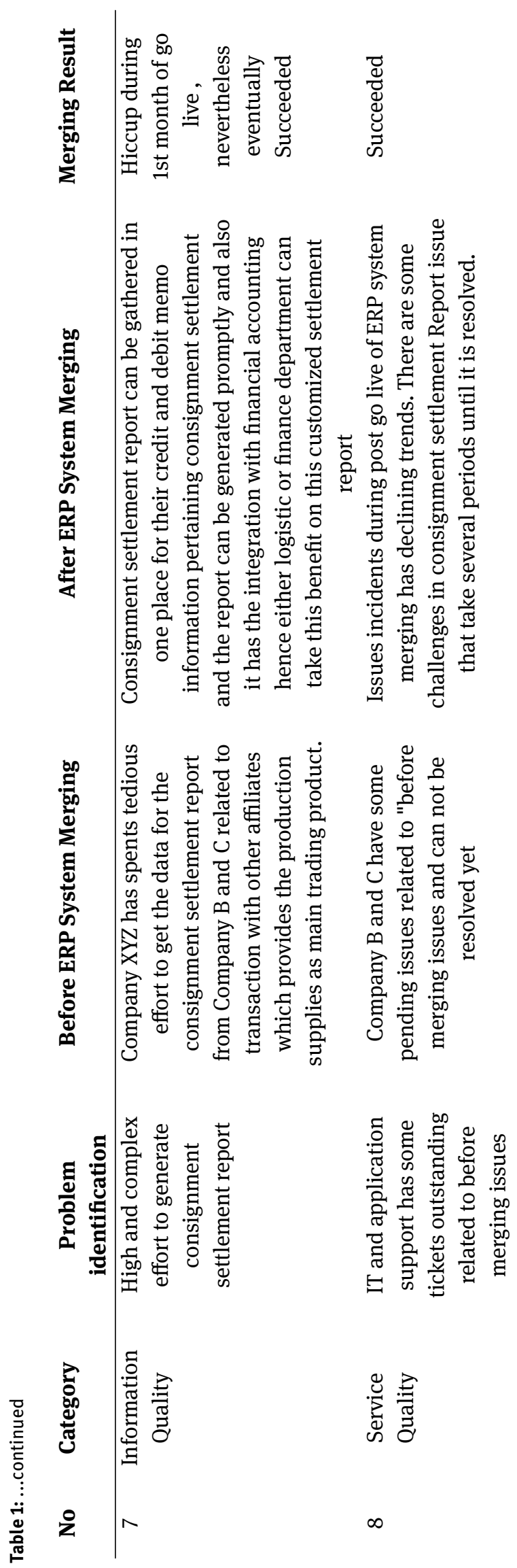




\section{Discussion}

The result shows that ERP System Merging succeed to increase the system quality of Chemical Company which acquired company B and company into one ERP system. It was depicted by the increment of easiness on using the system because of master data has been restructured in such way, hence user can find the required master data faster and more accurate. User now is able to do exercise in one integrate training environment which make them enthusiastic to learn new ways of working. The intercompany transaction is reduced drastically and company able to produce the balance sheet per profit center faster because of all data now in one Chemical Company. This result supports previous literature [10] which showed IT leveragability and knowledge sharing as key success factor of system quality success.

With the merging of the company B and company C into Chemical Company all the information regarding consignment settlement report can be gathered in one place for their credit and debit memo information pertaining consignment settlement and the report can be generated promptly and also it has the integration with financial accounting hence either logistic or finance department can take this benefit on this customized settlement report. Further analysis in ERP system merging related the increase of value in data as information after the system merging can be found clearly such as reconciled sales quantity and sales amount from one of the main transactions in consignment transaction. The information much more integrated and accurate after the ERP system merging. This analysis result was consonant with research by Hog Jiang $\mathrm{Xu}$ [13] information quality is essential for the success of system application success. Integrated data which was entered accurately also will impact on information quality itself.

After ERP system merging, the incidents ticket are reduced as the issues have been responded promptly and to minimize the waiting time for user to wait the solution to be delivered. Service quality was increased because of all data now in one system hence the problem can be localized and followed up by support team. ERP system merging success is one of the key factors for the companies who have implemented efficient incident log system as technology to speed up the responsiveness and also increase reliability of ERP Support Team. This analysis result is aligned with Seth and Deshmuk [9] which mentioned efficient customer care system is the key ingredients to service quality improvement.

The researcher recommends using this qualitative research to enrich the future research of information tech- nology success with DeLone and McLean measurements based on the findings during the research which may enrich the knowledge of information system success.

There are some challenges at the beginning of the merger implementation such as how to bring 3 existing business processes into one business process. Some alignment and fine-tuning in the process synchronization is made before the project start and during the project implementation, all business parties are involved and discussed the merging of business process which refers to main processes in Chemical Company which has established and verified by financial and IT audit with less area of improvement. Hence, in summary, the key success factors for the ERP system merging here are;

1. Chemical company has succeeded on ERP System merging in terms of system quality such as after the merging the system functionality has better features, ease of use, and more integrated, more accurate and agile to do customization across business unit. This success is powered up and governed by Top management as a steering committee in the project and as a project sponsor which that fully support the for significant the ERP system merging change impacts $\mathrm{s}$ either at organization level and ERP system being used.

2. Committed Business users as an employee of the merged companies either from the companies are being merged (Company $\mathrm{B}$ and Company $\mathrm{C}$ ) and from the key users from host Chemical Company to contribute their time and effort on business process and migration despite their day to day activities. This committed business user also has been supported by excellent IT and ERP support which brought the high level of responsiveness and decreasing number of incident along the way after ERP system merging go-live as key identifier for high quality standard of service quality

3. Reliable Chemical Company ERP system as the main reference for ERP system merging which has been audited by the third-party IT auditor made the ERP System merger process smoother and faster. especially in the giving better information quality such as logistic reports, HR report and Finance Report are now much reliable and meet ideal reports characteristics such as relevant, accurate, complete and concise 


\section{Conclusions}

Based on the analysis of Data Envelopment Analysis (DEA) in SAP $\mathrm{R} / 3$ implementation in the paper manufacturing business process, it was concluded that the SAP R/3 ERP system can help the paper manufacturing industry to integrate information from different business processes and provide centralized data linking in order to perfect the presentation of data, so as to facilitate the manufacturing industry in making decisions. Not yet in the implementation of SAP R/3 not only makes the company's manufacturing industry more efficient.

Many cases of SAP ERP R/3 implementation are successful, but the implementation of SAP SAP R / 3 does not always succeed in providing support for the efficiency of the company. There are several companies that failed in implementing SAP SAP R / 3 systems.

Therefore, analyzing and measuring the implementation of the ERP R / 3 system on the efficiency of business processes in a manufacturing industry is very important to learn about the importance of efficiency in business processes before and then implementing an ERP system. This research was conducted using the DEA (Data Envelopment Analysis) method using the Banxia Frontier Analysis program. According to Myers [11], DEA analysis (Data Envelopment Analysis) is specifically designed to measure the efficiency of a production unit in large numbers of inputs and many outputs, which one is more difficult to deal with openly with technical analysis of other efficiency improvements. One of the decisive problems in this method is how to determine variable input and output variables, which do not specify specifications in determining input and output variables, so that they determine input and output variables and are very subjective. But according to Harrison [19] generally the input variables are determined as resources used by the DMU (Decision Making Unit), while the temporary output is the profit generated as a result of activities carried out in the DMU (Decision Making Unit).

When variable input and output variables are determined in this study, there are several things that must be agreed upon, including: variable input and output used are components that affect the effectiveness of a company process, and include several DMUs (Decision Making Units) where each DMU (Decision Unit) is 2 periods before the ERP implementation and 2 periods after the SAP SAP $R$ / 3 implementation.

The variable input used in this study is the amount of production capacity in tons and the number of paper machines in the unit in the production planning division. The variables chosen as input variables in this study, be- cause of the variable production capacity and number of machines involved in the division planning process, without the number of machines and production capacity, the production activities cannot be carried out, while the output variable used in this study is the volume of production production planning division in tons. These variables are chosen because they are the result of business processes carried out by the production planning division.

Based on the analysis of the results of the efficiency measurements that have been made in the previous chapter, it can be determined the implementation of SAP R / 3 in the paper manufacturing industry for division planning must be efficient after ERP implementation compared to the period before ERP implementation. Can be seen from the measurement of each DMU before and after the ERP implementation, while the DMU that was approved in the period before the ERP implementation was $76.20 \%$, while the DMU after the SAP R / 3 implementation was $99.70 \%$.

\section{Recommendation}

\subsection{For Further Research}

The researcher recommends using this qualitative research to enrich the future research of information technology success with DeLone and McLean measurements based on the findings during the research which may enrich the knowledge of information system success, especially in ERP system merging topic.

There are some limitations on the research execution considering the number of informants is few only. Deep discussion with some topics is explained in detail and directly check the SAP system may cover the challenges. Hence in the future, the qualitative research on information system success may get more respondents and informants to dig out more details and get more details and variety of feedback from the informants in the company.

\subsection{For IT Practitioners}

Meanwhile researcher encourages IT practitioners to review and note down some points are highlighted in this ERP system merging success analyses research and use it as lesson learned for their day-today practice in information system workplace as lesson learned and use this research as a reference for the project implementation team to enrich the knowledge while preparing the ERP system 
merging in terms of project assessment, design, testing and implementation.

\section{References}

[1] Arachchi, S.C. (2015). Quality assurance and quality control in ERP systems implementation. American Scientific Research Journal for Engineering, Technology, and Sciences (ASRJETS), 8-083.

[2] Attayah, O. S. (2014). Impact of ERP system using on the accounting information relevance: evidence from Saudi Arabia. GSTF Journal on Business Review (GBR), 1-6.

[3] Barker, T. a. (2003). ERP implementation failure: A case study. Information System Management, 43-49.

[4] Beheshti, H. M. (2006). What managers should know about ERP/ERP II. Management Research News, 184-193.

[5] Belkhamza, Z. \&. (2012). Measuring Organizational Information Systems Success: New Technologies and Practices. Hershey: Business Science Reference (an imprint of IGI Global).

[6] Curko, K. S. (2012). Strategic success factors in ERP system implementation. Recent Researches in Business and Economics, 23-28.

[7] Davis, F. D. (1989). Perceived Usefulness, Perceived Ease of Use, and User Acceptance of Information Technology. MIS Quarterly, Vol. 13, No. 3, 319-340.

[8] DeLone, W. \&. (2003). The DeLone and McLean model of information systems success: A ten-year update. Journal of Management Information Systems, 19(4), 9-30.

[9] Deshmukh, S. \&. (2004). Service quality models: A review. International Journal of Quality \& Reliabilty Management, 33.

[10] Jaideep Motwani, D. M. (2002). Successful implementation of ERP projects: evidence from two case studies. International Journal of Production Economics, 75(1 - 2):83 - 96.

[11] Myers, M. V. (2008). Integration of different ERP systems - The case of merger and acquisition. Pacific Asia Conference on Information Systems (pp. 504-515). Suzhou: PACIS.
[12] Nah, F. F. (2001). Critical factors for successful implementation of enterprise systems. Business Process Management Journal, 7 (3), 285-296.

[13] Xu, H. (2015). What are the most important factors for accounting information quality and their impact on AIS data quality outcomes. ACM Journal of Data and Information Quality, vol. 5, no. 4, pp. 14:1-14:22.

[14] Mehta, M., \& Hirschheim, R. ; 2004. A framework for assessing IT integration decision-making in mergers and acquisitions. Paper presented at the 37th Annual Hawaii International Conference on System Sciences.

[15] Brown, C. V., Clancy, G., \& Scholer, R. J.; 2003. A Post-Merger IT Integration Success Story: Sallie Mae. MIS Quarterly Executive, 2(1), p.15-27.

[16] Henningsson, S.; 2007. Strategic Value of IS Integration in M\&AThe Relation between IS Integration and M\&A as a Tool for Corporate Strategy. Paper presented at the 40th Annual Hawaii International Conference on System Sciences.

[17] Sumi, T., \& Tsuruoka, M.; 2002. Ramp new enterprise information systems in a merger $\&$ acquisition environment: a case study. Journal of Engineering and Technology Management, 19(1), p.93104.

[18] Seddon, P. B., "A Respecification and Extension of the DeLone and McLean Model of IS Success"' Information Systems Research, 8, 3; 1997, p.240-253.

[19] Harrison, J. L; 2004 Motivations for enterprise resource planning (ERP) system implementation in public versus private sector organizations. (Ed.D., University of Central Florida). ProQuest Dissertations and Theses, . (305080817).

[20] Rai, A., Lang, S.S. and Welker, R.B.; 2002. "Assessing the Validity of IS Success Models: An Empirical Test and Theoretical Analysis", Information Systems Research", 13 (1), p. 50 (22). Academic one file. Web. 30 Dec. 2010. 